\title{
Vielversprechende Zoster-Impfung vor der Tür
}

\author{
Eine Vakzine mit dem rekombinaten Varizella-Zoster-Virus-Glykoprotein E verhindert zuverlässig \\ die Gürtelrose bei älteren Patienten und ist hoch effektiv gegen die postherpetische Neuralgie.
}

_ Mit Abnahme der Aktivität des Immunsystems im Alter kommt es häufig zur Reaktivierung eines latent vorhandenen Varizella-Zoster-Virus. Antivirale Substanzen verringern zwar die Dauer des Ausschlags, haben aber die Inzidenz der oft noch belastenderen postherpetischen Neuralgie nicht gesenkt.

An einer randomisierten, placebokontrollierten Phase-III-Studie, die in 18 Ländern durchgeführt wurde, nahmen 13.900 Personen im Alter über 70 Jahren teil. Der Hälfte von ihnen verabreichte man im Abstand von zwei Monaten zwei Dosen des Zoster-Impfstoffs HZ/su. Die andere Hälfte erhielt ein Placebo. Über eine mediane Nachbeobachtungszeit von 3,7 Jahren bekamen in der Placebogruppe 223 Probanden eine Zoster-Erkrankung, aber nur 23 in der HZ/suGruppe (9,2 vs. 0,9 pro 100.000 Personenjahre). Die Effektivität der Vakzine lag bei $89,8 \%$, wobei es keinen Unterschied machte, ob der Patient zwischen 70 und 79 Jahre alt war oder älter. Die Häufigkeit einer Post-Zoster-Neuralgie war bei den wenigen Erkrankten in der Verumgruppe wesentlich geringer als bei jenen in der Placebogruppe.

An Nebenwirkungen ist eine lokale Entzündungsreaktion innerhalb von sieben Tagen an der Injektionsstelle erwähnenswert, die bei fast $80 \%$ der Patienten in der Verumgruppe auftrat, in der Pla- cebogruppe jedoch nur bei $30 \%$. Schwerwiegende Nebenwirkungen, insbesondere potenziell immunvermittelte Systemerkrankungen und Todesfälle, kamen in beiden Gruppen gleich häufig vor.

- Cunningham AL et al. Efficacy of the herpes zoster subunit vaccine in adults 70 years of age or older. $N$ Engl $\mathrm{J} \mathrm{Med.}$ 2016;375:1019-32

\section{KOMMENTAR}

Bedenkt man die oft langwierigen und sehr unangenehmen Krankheitsverläufe älterer Menschen beim Zoster, so dürfte diese Impfung eine willkommene Bereicherung des Präventionsprogramms im höheren Lebensalter werden.

Prof. Dr. med. H. S. FüeßI

\section{Hier steht eine Anzeige.}

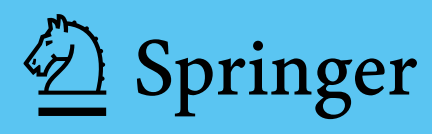

